\title{
Pengaruh temperatur elektrolit terhadap ketebalan dan kuat lekat baja karbon rendah pada proses elektroplating
}

\author{
Asroni ${ }^{1}$, Eko Budiyanto ${ }^{2}$, Tri Cahyo Wahyudi ${ }^{*}$, I Wayan Suarca ${ }^{4}$ \\ 1, 2, 3Jurusan Teknik Mesin, Fakultas Teknik, Universitas Muhammadiyah Metro \\ JI. Ki Hajar Dewantara 15 A Kota Metro, Lampung, Indonesia \\ ${ }^{4}$ Prodi Teknik Mesin, Fakultas Teknik, Universitas Muhammadiyah Metro \\ Jl. Ki Hajar Dewantara 15 A Kota Metro, Lampung, Indonesia \\ ${ }^{*}$ Corresponding author: tricahyowahyudi3@gmail.com
}

\begin{abstract}
The development of industry as well as science and technology requires humans to fulfill various kinds of needs in their lives. One of them is the need for metal-based goods. Many objects around us, both in the automotive industry and in the steel-based industry for household purposes, etc., are given a metallic finish to protect and beautify the metal. The metal coating technique that is often used in the metal industry is electroplating. Electroplating comes from two words, namely electro and plating or electricity and coating that uses a deposition system. The purpose of this study was to determine the effect of electrolyte temperature on the thickness and adhesive strength of low carbon steel in the electroplating process. The cathode used is low carbon steel with dimensions of $70 \mathrm{~mm} \times 25 \mathrm{~mm} \times 20 \mathrm{~mm}$, while the anode used is Nickel (Ni) and the bath for plating is $60 \mathrm{~cm}$ long, $30 \mathrm{~cm}$ depth, and $30 \mathrm{~cm}$ wide. Two anodes on the right and left side of the anode with an anode-cathode distance of $10 \mathrm{~cm}$, and using an electric voltage of 7.5 Volts, and using variations in electrolyte temperature of $45^{\circ} \mathrm{C}, 50^{\circ} \mathrm{C}, 55^{\circ} \mathrm{C}, 60^{\circ} \mathrm{C}$, $65^{\circ} \mathrm{C}$ and room temperature. From the results of the study found the optimal thickness value with $0.021 \mathrm{~mm}$ at a temperature of $60^{\circ} \mathrm{C}$. Meanwhile, the optimal value for coating adhesive strength from electroplating research is $60^{\circ} \mathrm{C}$ with a very high adhesive strength value of 26.53 $M P a$.
\end{abstract}

Keywords: Electroplating, cathode, anode, nickel, temperature.

\begin{abstract}
Abstrak
Perkembangan industri serta ilmu pengetahuan serta teknologi mengharuskan manusia untuk memenuhi berbagai macam kebutuhan hidupnya. Salah satunya adalah kebutuhan akan barang berbahan dasar logam. Banyak benda disekitar kita baik dalam industri otomotif maupun industri berbahan dasar baja untuk keperluan rumah tangga dan lain sebagainya yang diberi sentuhan akhir berupa lapisan logam untuk melindungi maupun memperindah logam tersebut. Teknik pelapisan logam yang sering kali digunakan dalam industri logam yaitu elektroplating. Elektroplating berasal dari dua kata yaitu elektro dan plating atau listrik dan pelapisan yang menggunakan sistem pengendapan. Tujuan penelitian adalah untuk mengetahui pengaruh temperatur elektrolit terhadap ketebalan dan kuat lekat baja karbon rendah pada proses elektroplating. Katoda yang digunakan baja karbon rendah dengan ukuran dimensi 70 $\mathrm{mm}$ x $25 \mathrm{~mm}$ x $20 \mathrm{~mm}$ sedangkan anoda yang digunakan nikel (Ni) serta bak untuk melakukan pelapisan menggunakan dengan panjang $60 \mathrm{~cm}$, tinggi $30 \mathrm{~cm}$, dan lebar $30 \mathrm{~cm}$, Metode yang digunakan dalam penelitian ini yaitu dengan dua anoda yang berada disisi kanan dan sisi kiri anoda dengan jarak anoda-katoda $10 \mathrm{~cm}$, dan menggunakan tegangan listrik sebesar 7,5 Volt, serta menggunakan variasi temperatur elektrolit $45^{\circ} \mathrm{C}, 50^{\circ} \mathrm{C}, 55^{\circ} \mathrm{C}, 60^{\circ} \mathrm{C}, 65^{\circ} \mathrm{C}$ dan temperatur ruang. Dari hasil penelitian ditemukan nilai ketebalan optimal dengan $0,021 \mathrm{~mm}$ pada temperatur $60^{\circ} \mathrm{C}$. Sedangkan nilai kuat lekat optimal lapisan dari penelitian elektroplating terdapat pada variasi $60^{\circ} \mathrm{C}$ dengan nilai kuat lekat sangat tinggi $26,53 \mathrm{MPa}$.
\end{abstract}


Kata kunci: Elektroplating, katoda, anoda, nikel, temperatur.

\section{Pendahuluan}

Perkembangan industri dan kemajuan ilmu pengetahuan serta teknologi mengharuskan manusia untuk memenuhi berbagai macam kebutuhan hidupnya. Salah satunya adalah kebutuhan akan barang berbahan dasar logam. Logam baja merupakan material konstruksi yang sering kali diaplikasikan pada berbagai macam struktur karena memilki sifat mekanik yang baik serta mudah difabrikasi. Banyak benda disekitar kita baik dalam industri otomotif maupun industri berbahan dasar baja untuk keperluan rumah tangga dan lain sebagainya yang diberi sentuhan akhir berupa lapisan logam untuk melindungi maupun memperindah logam tersebut. Teknik pelapisan logam yang sering kali digunakan dalam industri logam yaitu elektroplating. Elektroplating adalah proses pelapisan yang menggunakan prinsip pengendapan logam dengan cara elektrokimia. Benda kerja yang akan dilapisi dijadikan katoda. Sedangkan logam yang akan melapisi benda kerja dijadikan anoda. Kelebihan menggunakan cara ini, yaitu mudah dilakukan dan hasil yang baik serta murah dalam ongkos produksinya [1].

Elektroplating merupakan salah satu proses pelapisan yang memanfaatkan prinsip elektrokimia. Sehingga untuk mendapatkan pengetahuan yang lebih mendalam dari formulasi dan komposisi dari larutan, maka pengetahuan tentang ilmu kimia sangat dibutuhkan. Teknologi pelapisan juga memakai zat adiktif tetapi hingga saat ini zat adiktif yang ada dirahasiakan, sehingga informasinya terbatas dan hanya tersedia dalam bentuk patennya. Dalam elektroplating arus dan distribusinya merupakan parameter yang sangat penting bila dibandingkan dengan potensial, karena biasa digunakan sebagai pengendali dari hasil pelapisan Perlu diketahui dalam proses elektroplating faktor kerapatan arus, voltase (tegangan) dan suhu elektrolit sangat menentukan hasil akhir daripada elektroplating. Suhu atau temperatur merupakan ukuran panasdingingya suatu zat, dalam penelitian ini dikaitkan dengan ukuran panas-dinginya larutan elektrolit [2].

Berdasarkan uraian di atas, maka perlu dilakukan penelitian untuk mengetahui pengaruh temperatur elektrolit terhadap ketebalan dan kuat lekat baja karbon rendah pada proses elektroplating, yang menerapkan variabel temperatur proses elektroplating diantaranya ketebalan serta kuat lekat. Dimana kelekatan pelapisan sangat menentukan ketahanan terhadap korosi yang akan dialami oleh material tersebut

\section{Tinjauan Pustaka}

\section{Pelapisan Logam}

Seiring dengan pesatnya perkembangan teknologi menuntut para pelaku industri untuk terus berinovasi dan menghasilkan produk-produk industri yang dapat diterima oleh konsumen. Terkhusus untuk pelapisan logam saat ini sudah tidak asing lagi dalam dunia industri, bahkan sampai masyarakat umum juga sebagian sudah mengenal pelapisan logam dengan menggunakan listrik atau elektroplating. Faktor ekonomis, kekuatan struktural, keawetan dan agar terlindungi dari korosi adalah alasan adanya finishing, finishing bisa berupa pengecatan atau elektroplating [3].

Pelapisan logam juga dapat dilakukan dengan metode kimiawi yaitu elektroplating dengan konsep mencelupkan dua buah benda elektroda yang masingmasing disebut dengan katoda dan anoda ke dalam larutan elektrolit yang bersifat asam dan dengan bantuan energi listrik DC untuk menghasilkan aliran supaya senyawa yang terdapat dikatoda berpindah ke anoda yang merambat melalui media larutan elektrolit [4].

\begin{tabular}{llrr}
\multicolumn{2}{c}{ Pelapisan Untuk Sifat Khusus } \\
Permukaan ini bertujuan untuk \\
mendapatkan & sifat khusus permukaan
\end{tabular}


seperti sifat keras, sifat tahan aus dan sifat tahan suhu tinggi atau gabungan dari beberapa tujuan diatas secara bersamasama. Misalnya dengan melapisi bantalan dengan logam nikel agar bantalan lebih keras dan tidak mudah aus akibat gesekan pada saat berputar.

\section{Elektroplating}

Proses elektroplating adalah proses pelapisan dimana terjadi pengendapan suatu pelapis logam tipis pada permukaan yang dilapisi menggunakan arus listrik searah dan tegangan yang konstan [5]. Elektroplating berasal dari dua kata dasar yaitu elektro dan plating atau listrik dan pelapis yang mempunyai arti bahwa dalam suatu pelapisan yang disebut elektroplating adalah suatu pelapisan di mana pelapisan itu menggunakan listrik untuk melapisi logam antara bahan pelapis (anoda) dan yang akan di lapisi (katoda), dengan menggunakan arus listrik searah (DC), pada prinsip kerjanya logam akan mengalami perubahan kimia secara fisik salah satu dari logam tersebut akan yang melepaskan ion-ion dan sebaliknya ada yang akan mengikat ion-ion yang terlepas akibat adanya energi listrik [6].

Dalam pelaksanaan proses elektroplating ada beberapa hal yang perlu diperhatikan yaitu arus yang diperlukan untuk melapisi dalam proses elektroplating (rapat arus), termperatur larutan, waktu pelapisan dan konsentrasi larutan. Dalam proses pelapisan nikel temperatur elektrolit juga sangat menetukan hasil pelapisan temperatur diatur sesuai dengan ketentuan yang ada, untuk meratakan distribusi ion nikel agar supaya ketebalan yang diperoleh sama maka dalam proses elektroplating dibutuhkan pengaduk dengan mengunakan udara dengan cara dihembuskan melalui kompresor kedalam elektrolit, bisa juga secara mekanik yaitu diaduk langsung dengan menggunakan pengaduk.

\section{Baja}

Baja adalah adalah salah satu logam yang paling banyak dipakai dibanding dengan logam-logam lainnya, pada dasarnya baja adalah campuran besi, karbon dan sedikit unsur-unsur lain yang disebut sebagai baja karbon lain (Carbon steel). Jika unsur-unsur lain yang ada pada baja berjumlah dengan kadar yang besar maka akan menyebabkan perubahan pada sifatnya yang sering disebut dengan baja paduan [7]. Baja Karbon Rendah (Low Carbon Steel) disebut baja ringan (mid steel) atau baja perkakas, baja karbon rendah bukan baja yang keras, karena kandungan karbonnya rendah kurang dari 0,3\%. Baja ini dapat dijadikan mur, baut, ulir sekrup, peralatan senjata, alat pengangkat presisi, batang tarik, perkakas silinder, dan penggunaan yang hampir sama. Penggilingan dan penyesuaian ukuran baja dapat dilakukan dalam panas. Hal itu dapat ditandai dengan melihat lapisan oksida besinya di bagian permukaan yang berwarna hitam. Baja juga dapat diselesaikan dengan pengerjaan dingin dengan cara merendam atau mencelupkan baja ke dalam larutan asam yang berguna untuk mengeluarkan lapisan oksidanya. Setelah itu, baja diangkat dan digiling sampai ukuran yang dikehendaki, selanjutnya didinginkan. Proses ini menghasilkan baja yang lebih licin, sehingga lebih baik sifatnya dan bagus untuk dibuat mesin perkakas.

Baja karbon rendah banyak digunakan untuk proses pembentukan logam lembaran, misalnya untuk badan dan rangka kendaraan serta komponenkomponen otomotif lainnya. Baja jenis ini dibuat dan diaplikasikan dengan mengeksploitasi sifat-sifat ferrite. Ferrite adalah salah satu fasa penting di dalam baja yang bersifat lunak dan ulet. Baja karbon rendah umumnya memiliki kadar karbon di bawah komposisi eutectoid dan memiliki struktur mikro hampir seluruhnya ferrite. Pada lembaran baja kadar karbon sangat rendah atau ultra rendah, jumlah atom karbonnya bahkan masih berada dalam batas kelarutannya pada larutan padat sehingga struktur mikronya adalah ferrite seluruhnya. Hingga batas kelarutannya di dalam larutan padat ferrite, penambahan karbon 
berpengaruh terhadap sifat-sifat mekanik lembaran [8].

\section{Ketebalan elektroplating}

Ketebalan pelapisan adalah salah satu syarat penting dari suatu lapisan hasil elektroplating. Dengan demikian di pilih salah satu pengujian dari sekian banyak jenis pengujian yang dilakukan terhadap hasil pelapisan elektroplating,oleh itu ketebalan permukaan adalah salah satu uji yang harus dilakukan.

Dalam merencanakan pengukuran ketebalan yang perlu diperhatikan adalah kejelasan pengukuran ketebalan yang diinginkan, yaitu ketebalan rata-rata atau ketebalan pada lokasi atau titik tertentu yang sangat strategis. Dalam hal ini diambil ketebalan rata-rata karena distribusi ketebalan yang sama disetiap titik pada suatu permukaan yang dilapisi jarang sekali bisa dihasilkan dengan proses elektroplating

\section{Metode Penelitian}

Penelitian ini dilakukan di Laboratorium Teknik Mesin Universitas Muhammadiyah Metro.

Alat

1) Bak elektroplating

2) Gerinda

3) Water Heater ( Pemanas larutan )

4) Penggaris / mistar

5) Stopwatch

6) Mikrometer Skrup

7) Universal Testing Machine $1000 \mathrm{kn}$ With Digital Adr + Computer Universal

8) Power Supply

9) Multimeter

10) Amplas

11) Termometer

12) Kabel listrik

Bahan

1) Baja karbon rendah (ST41)

2) Nikel (Ni)

3) Larutan elektrolit asam sulfat $\left(\mathrm{H}_{2} \mathrm{SO} 4\right)$

4) Nikel Sulfat $\left(\mathrm{NiSO}_{4}\right)$

5) Larutan pembersih alkali
Prosedur Penelitian

1) Mempersiapkan bahan, dalam hal ini pelat baja karbon rendah (katoda),

2) Mempersiapkan larutan elektrolit asam sulfat $\left(\mathrm{H}_{2} \mathrm{SO} 4\right)$

3) Pembuatan specimen, memotong pelat baja dengan dimensi $70 \mathrm{~mm} \times 25 \mathrm{~mm}$ x $20 \mathrm{~mm}$,

4) Membersihkan dan menghaluskan permukaan specimen mengunakan gerinda,

5) Mengukur ketebalan specimen untuk mengetahui perbandingan setelah pengujian,

6) Merendam specimen dengan menggunakan larutan alkali selama 5 menit, lalu keringkan

7) Menghubungkan spesimen pada arus listrik negatif dan logam nikel dihubungkan pada arus listrik positif,

8) Menyiapkan larutan elektrolit sesuai dengan variasi yang ditentukan, dengan cara dipanaskan. Variasinya ( suhu ruangan, $45^{\circ} \mathrm{C}, 50{ }^{\circ} \mathrm{C}, 55^{\circ} \mathrm{C}, 60$ ${ }^{\circ} \mathrm{C}, 65^{\circ} \mathrm{C}$ )

9) Mengatur tegangan (V) yang telah ditentukan nilainya,

10) Mencelupkan logam nikel kedalam bak larutan,

11) Mencelupkan specimen kedalam bak larutan dengan jarak $10 \mathrm{~cm}$,

12) Menghidupkan stopwatch bersamaan dengan mencelupkan specimen kedalam bak larutan,

13) Mengangkat specimen pada waktu yang telah ditentukan,

14) Membersihkan specimen dengan menggunakan air,

15) Lakukan pengujian ketebalan dan kerekatan pada specimen. 


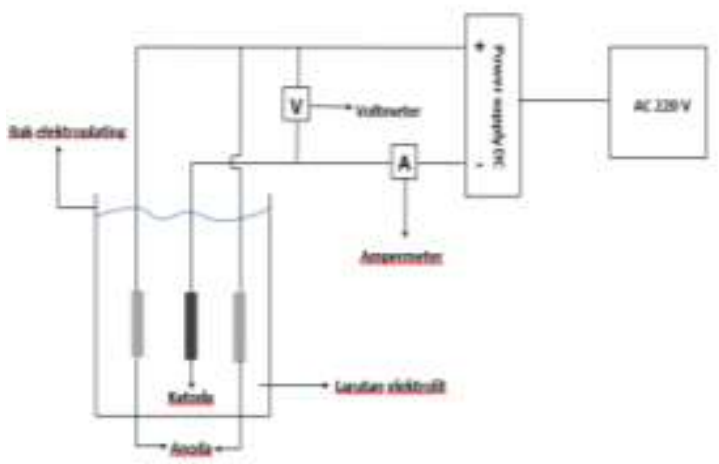

Gambar 1. Skematis Rangkaian Pelapisan Listrik.

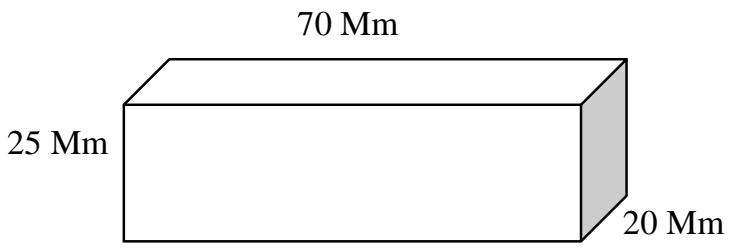

Gambar 2. Gambar Ukuran Spesimen.

\section{Hasil dan Pembahasan}

Pada tahap pengujian mendapatkan hasil yang akan dianalisa dan kemudian dapat diambil kesimpulan. Pengujian yang dilakukan adalah pengujian ketebalan menggunakan Mikrometer Skrup dan pengujian kuat lekat dengan Universal Testing Machine 1000 kN With Digital Adr + Computer yang dilakukan di Laboratorium Teknik Mesin Universitas Muhammadiyah Metro.

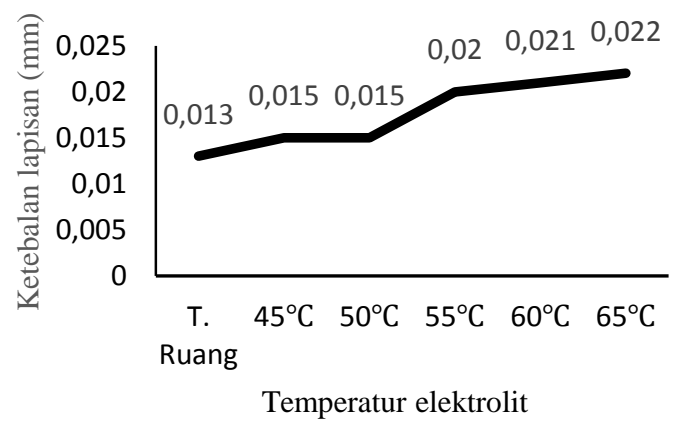

Gambar 3. Hasil pengujian ketebalan

Dari gambar no 3 diatas dapat kita ketahui nilai ketebalan lapisan pada setiap variasi yaitu pada suhu ruangan dengan nilai $0,013 \mathrm{~mm}$, pada suhu $45^{\circ} \mathrm{C}$ dengan nilai $0,015 \mathrm{~mm}$, pada suhu $50^{\circ} \mathrm{C}$ dengan ilia 0,015 $\mathrm{mm}$, pada suhu $55^{\circ} \mathrm{C}$ dengan nilai $0,02 \mathrm{~mm}$, pada suhu $60^{\circ} \mathrm{C}$ dengan nilai $0,021 \mathrm{~mm}$ dan yang terakhir pada suhu $65^{\circ} \mathrm{C}$ dengan nilai 0,022 $\mathrm{mm}$. dengan begitu diketahui bahwa ketebalan optimal pada penelitian ini diperoleh pada variasi suhu $65^{\circ} \mathrm{C}$ sebesar $0,022 \mathrm{~mm}$.

Hal ini dapat dinyatakan bahwa semakin tinggi atau semakin rendah temperatur elektrolit akan berpengaruh terhadap nilai ketebalan, semakin tinggi temperaturnya maka semakin tebal lapisannya, dilihat dari variasi suhu ruangan sampai dengan $65^{\circ} \mathrm{C}$ ketebalannya terus meningkat. Hal ini juga berbanding lurus dengan penelitian Andriawan pada tahun 2019, yang mengatakan "semakin tinggi temperatur elektrolit dan semakin lama proses yang digunakan maka semakin tebal lapisan nikel yang terbentuk sedangkan kekerasan permukaan lapisan nikel baja ST41 semakin menurun" [1].

Begitu juga pada penelitian sebelumnya yang mengatakan "temperatur sangat berpengaruh pada tampak fisik, ketebalan dan kekerasan. Semakin tinggi temperatur maka hasil pelapisan semakin tebal dan mengkilap" [9].

Untuk hubungan hasil pengujian pengaruh temperatur elektrolit dengan kuat lekat pada proses elektroplating dapat dilihat pada diagram berikut.

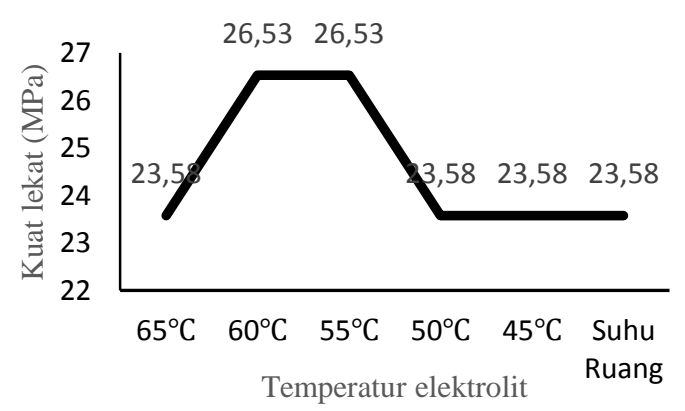

Gambar 4. Hasil pengujian kuat lekat

Dari gambar 4 dapat kita ketahui nilai kuat lekat hasil pelapisan pada setiap variasi yaitu pada suhu ruangan atau tanpa dipanaskan elektrolitnya dengan nilai 23,58 $\mathrm{MPa}$, pada suhu $45^{\circ} \mathrm{C}$ dengan nilai 23,58 $\mathrm{MPa}$, pada suhu $50^{\circ} \mathrm{C}$ dengan nilai 23,58 Mpa, pada suhu $55^{\circ} \mathrm{C}$ dengan nilai 26,53 $\mathrm{MPa}$, pada suhu $60^{\circ} \mathrm{C}$ dengan nilai 26,53, dan 
yang terakhir pada suhu $65^{\circ} \mathrm{C}$ dengan nilai 23,58 . Sehingga dapat kita ketahui nilai kuat lekat optimal terjadi pada variasi temperatur $60^{\circ} \mathrm{C}$ dan $50^{\circ} \mathrm{C}$, akan tetapi hasil uji pada variasi $50^{\circ} \mathrm{C}$ terjadi pengelupasan pada lapisan dan pada variasi temperatur $60^{\circ} \mathrm{C}$ tidak ada lapisan yang mengelupas.

Dengan begitu dapat dinyatakan bahwa nilai kuat lekat optimal terjadi pada variasi temperatur $60^{\circ} \mathrm{C}$ dengan nilai kuat lekat 26,53 MPa. Semakin tinggi temperatur maka semakin tinggi nilai kuat lekat, tapi jika lebih dari temperatur $60^{\circ} \mathrm{C}$ nilai kuat lekat spesimen akan kembali turun dengan permukaan lapisan dari spesimen tersebut sedikit terbakar sehingga mempengaruhi laju korosi nantinya.

Nilai kuat lekat juga akan mempengaruhi laju korosi, akan tetapi laju korosi berbanding terbalik dengan kuat lekat, semakin tinggi nilai kuat lekat semakin menurun laju korosinya. Begitu juga pada penelitian Alphanoda yang mengatakan "semakin tinggi temperatur elektrolit, maka laju korosi pada baja yang dilakukan proses elektrolpating akan semakin menurun" [10].

Temperatur terlalu rendah dan rapat arus yang cukup optimum mengakibatkan hasil pelapisan menjadi kasar dan kusam, tetapi jika temperatur tinggi dengan rapat arus yang optimum maka, hasil pelapisan menjadi tidak merata. Kenaikan temperatur menyebabkan kenaikan konduktifitas dan disfusitas larutan elektrolit, yang berarti tahanan elektrolit mengecil sehingga potensial yang dibutuhkan untuk mereduksi ion-ion menjadi logam berkurang [11].

Tabel 1. Indikator kualitas

\begin{tabular}{|c|c|c|c|c|}
\hline No & temperatur & visual & Мpa & mm \\
\hline 1 & $65^{\circ} \mathrm{C}$ & $\begin{array}{l}\text { Setiap Sudut } \\
\text { Gosong Dan } \\
\text { Tidak Rata }\end{array}$ & 23,58 & 0,022 \\
\hline 2 & $60^{\circ} \mathrm{C}$ & $\begin{array}{l}\text { Mengkilap, halus } \\
\text { Dan Bersih }\end{array}$ & 26,53 & 0,021 \\
\hline 3 & $55^{\circ} \mathrm{C}$ & Halus Dan Bersih & 26,53 & 0,02 \\
\hline 4 & $50^{\circ} \mathrm{C}$ & $\begin{array}{l}\text { Halus, tidak } \\
\text { mengkilap }\end{array}$ & 23,58 & 0,015 \\
\hline 5 & $45^{\circ} \mathrm{C}$ & $\begin{array}{l}\text { Tipis, tidak } \\
\text { mengkilap }\end{array}$ & 23,58 & 0,015 \\
\hline 6 & T. ruang & $\begin{array}{l}\text { Tipis, tidak } \\
\text { mengkilap }\end{array}$ & 23,58 & 0,013 \\
\hline
\end{tabular}

Berdasarkan tabel indikator kualitas, didapatkan nilai optimal untuk ketebalan dengan nilai $0,021 \mathrm{~mm}$ dan nilai kuat lekat dengan nilai 26,53 Mpa pada temperatur $60^{\circ} \mathrm{C}$

Maka semakin tinggi temperatur maka semakin tinggi nilai kuat lekat dan ketebalan semakin naik, tapi jika lebih dari temperatur $60^{\circ} \mathrm{C}$ nilai kuat lekat spesimen akan kembali turun dengan permukaan lapisan dari spesimen tersebut sedikit terbakar sehingga mempengaruhi laju korosi nantinya. Kenaikan temperatur elektrolit berbanding lurus terhadap nilai ketebalan dan kuat lekat namun hanya sampai temperatur $60^{\circ} \mathrm{C}$. Karena kenaikan temperatur menyebabkan kenaikan konduktifitas dan disfusitas larutan elektrolit, yang berarti tahanan elektrolit mengecil sehingga potensial yang dibutuhkan untuk mereduksi ion-ion menjadi logam berkurang [11].

\section{Kesimpulan}

Kesimpulan yang didapat dari penelitian ini yaitu, variasi temperatur optimal $60^{\circ} \mathrm{C}$ dengan nilai ketebalan 0,021 $\mathrm{mm}$ dan nilai kuat lekat 26,53 Mpa.

\section{Referensi}

[1] Andriawan, dkk 2019, Pengaruh temperatur dan waktu proses elektroplating terhadap struktur mikro, ketebalan dan kekerasan lapisan nikel baja St41, Jurusan Teknik Mesin Fakultas Teknik Universitas Negeri Surabaya.

[2] Muhammad, R Kurniawan 2019, Pengaruh temperatur dengan konsesntrasi elektrolit terhadap hasil elektroplating tembaga pada baja karbon rendah. Jurnal polimesin jurusan teknik mesin.

[3] Rasyad, Abdul dkk 2018, Analisa pengaruh temperatur, waktu, dan kuat arus proses elektroplating terhadap kuat tarik, kuat tekuk dan kekerasan pada baja karbon rendah, 
Prodi Teknik Mesin Fakultas Teknik UKI Jakarta.

[4] Permadi, Billy dkk 2019, Proses elektroplating nikel dengan variasi jarak anodakatoda dan tegangan listrik pada baja ST-41, Prodi Teknik Mesin Fakultas Teknik Universitas Muhammadiyah Metro.

[5] Nasution, S. F. 2011. Pelapisan Krom pada Baja Karbon Rendah dengan Metode Elektroplating sebagai Anti Korosi.

[6] Sutomo, S. (2010). Pengaruh Arus dan Waktu pada Pelapisan Nikel dengan Elektroplating untuk Bentuk Plat.

[7] Fatoni, Z. (2016). Pengaruh perlakuan panas terhadap sifat kekerasan baja paduan rendah untuk bahan pisau penyayat batang karet. Jurnal Desiminasi Teknologi.

[8] Yuhda, K, A., Irfan, S, A., Amiadji. (2015). Analisa Laju Korosi Pada Pelat Baja Karbon Dengan Variasi Ketebalan Coating. Jurnal Teknik ITS

[9] Widodo, B,. (2009). Analisa Perlakuan Panas Normalising Pada Pengelasan Argon Terhadap Sifat Mekanik Hasil Las Baja Karbon Rendah. Jurnal Teknologi Technoscientia.

[10] Alphanoda, Fahreza A. 2019, Pengaruh temperatur larutan elektrolit dan jarak elektroda terhadap laju korosi pada hasil pelapisan elektroplating Hard Chrome, Program Studi Teknik Mesin Politeknik Sukabumi.

[11] Yetri Yuli, Marsedi Ultra,dkk (2020). Pengaruh Waktu Dan Temperatur Larutan Terhadap Ketebalan Dan Kekerasan Permukaan Lapisan Hasil Elektroplating Kuningan Pada Baja. Jurnal Teknologi Manufaktur, Politeknik Negeri Padang 